Selection and Reporting Bias in Household Surveys of Child Labor:

Evidence from Tanzania

by

\author{
Yohanne N. Kidolezi \\ Jessica A. Holmes \\ Hugo Ñopo \\ Paul M. Sommers
}

D epartment of Economics

Middlebury College

Middlebury, Vermont 05753

JEL \#s: 055, J49

DEPARTMENT OF ECONOMICS
MIDDLEBURY COLLEGE
MIDDLEBURY, VERMONT 05753

http:/ / www.middlebury.edu/ econ 
Selection and Reporting Bias in Household Surveys of Child Labor:

Evidence from Tanzania

by

Yohanne N. Kidolezi

Jessica A. Holmes

Hugo Ñopo

Paul M. Sommers

Department of Economics

Middlebury College

Middlebury, Vermont 05753

JEL \#s: O55, J49 


\section{Selection and Reporting Bias in Household Surveys of Child Labor: Evidence from Tanzania}

Studies of child labor in developing countries have largely relied on data collected through national household surveys. But, government-sponsored household surveys are arguably prone to both sample selection bias and reporting bias. In this paper, we compare the demographic and labor market characteristics of working street children obtained from the 2000 Tanzanian Integrated Labor Force Survey, a government-sponsored household survey, with the results obtained in a 2004 survey of working street children in the city of Mwanza in northern Tanzania. Our comparisons help illumine the potential biases introduced when child labor studies rely on household samples; specifically, we show that children in the non-household based survey work longer hours, have lower educational attainment and suffer worse health outcomes than their counterparts in the government-sponsored household survey. This suggests that studies based on national household surveys may significantly underestimate both the extent and the consequences of child labor.

\section{Introduction}

Studies have shown that the participation of children under the age of 18 in the labor market is associated with lower educational attainment and delayed development of basic literacy and quantitative skills (Patrinos and Psacharopoulos, 1997; Akabayashi and Psacharopoulos, 1999). Moreover, long hours of exposure to street dust, dirt, environmental chemicals, and drugs pose serious hazards to working children's physical health while parental absence adversely affects their mental health (Hecht, 1998 and Fassa et al., 1999). Employers may take advantage of children's poor bargaining power because children cannot legally form unions. As a consequence, employers subject children to working conditions that adult workers would not tolerate (Gustafsson-Wright and Pyne, 2002). 
Despite the magnitude of the problem, the topic of child labor has only recently received widespread academic attention (Admassie, 2002). Yet, most of the studies which have sought to improve our understanding of the individual, household, and community-level determinants of child labor in developing countries rely on national household surveys administered by government statistical bureaus (for examples, Patrinos and Psacharopoulos, 1995; Jensen and Nielsen, 1997; Grootaert, 1998; Blunch and Verner, 1999; Canagarajah and Coulombe, 1999; Ray, 2000, 2002; Lopez-Acevedo, 2002; and Beegle, Dehejia, and Gatti, 2005). Household surveys are, however, flawed for several reasons. First, household surveys may be prone to sample selection bias. Large numbers of child workers, especially those working in the streets of urban areas of developing countries, may not live in "households" or even have a permanent residence. In sub-Saharan Africa, for example, the AIDS epidemic has left many children orphaned (see Arndt and Lewis, 2000 and Arndt and Wobst, 2002), who are not affiliated with any household or permanent residence. Second, household surveys may also be prone to reporting bias. Since child labor is illegal in most countries, ${ }^{1}$ heads of households are likely to underreport their children's labor market activities so that parents (who are usually the principal interviewees) appear law-abiding.

This paper contributes to the child labor literature along several dimensions. First, by comparing the demographic, educational, labor market, and health characteristics of child street laborers obtained from Tanzania's 2000 survey of the labor force, a household survey, with the results obtained in a 2004 survey of working street children in Mwanza, Tanzania, we hope to better understand the potential bias introduced when child labor studies rely on household samples. Second, we test for the presence of reporting bias from household heads when confronted to give information about the labor participation of their children. Lastly, little is known about the lives and the context of children working in the streets. We hope that this study of working street children in Tanzania will be a valuable addition to the limited literature on this topic. 
The paper is organized into four sections. Section II describes the methodology for the field survey. Section III presents the empirical results and detailed comparisons of survey samples. Section IV concludes.

\section{Methodology}

This study targeted children ranging in age from 5 to 17 who work in the streets of the city of Mwanza in northern Tanzania. With about 480,000 inhabitants, Mwanza is Tanzania's second largest urban center (http://www.tanzania.fo.tz ). Most of its residents are fishermen who depend on Lake Victoria, which borders the city to the north and east.

In the streets of Mwanza, children's labor is divided into three categories. The first category comprises vending or peddling perishable food, non-perishable food, or non-food items such as newspapers and cigarettes. The second category includes productive activities such as washing cars, gathering sand, or carrying luggage. Unproductive activities, such as begging for money or food, make up the last category. Since there is no formal training involved, children learn workplace skills from their parents, siblings, employers, or friends. Consequently, specialization in a particular activity occurs on the basis of physical ability, personal choice, or parent/relative/employer preferences.

Depending on the type of job, employment decisions such as workload or time spent working vary according to employer. Self-employed children, for example, can decide how long they should work or where they want to conduct their activities. Those employed by their parents or other relatives may enjoy some degree of autonomy in their work. However, children typically have little or no autonomy when they work for an unrelated person. Children employed by unrelated persons thus tend to be the most disadvantaged of all street workers in Mwanza.

The survey questionnaire (available from the authors on request) contains 69 questions on the demographic, educational, labor market, and health status of working street children., ${ }^{2,3}$ Between June 14 and July 25, 2004, a total of 350 children in the urban wards of Mwanza were 
approached, of whom 321 agreed to be interviewed and complete the questionnaire. ${ }^{4}$ All interviewees who participated in the survey received compensation in the form of cash (enough to cover the cost of lunch) or small presents (such as notebooks or colored pens). The amount or type of compensation was not disclosed to the subject until the interview was completed so as to eliminate any possible influence on the interviewees' responses.

Our results were compared to those obtained from Tanzania's Integrated Labor Force Survey (hereafter, ILFS) from 2000-2001. The ILFS, a household-based survey, was conducted by Tanzania's National Bureau of Statistics and was funded by the Danish International Development Agency. Since each observation in the ILFS data set is coded for region, district, ward, and household, it was possible to identify data on working street children between the ages of 5 and 17 from all urban wards in Mwanza that geographically match the area covered in our survey. There are three datasets with which to compare the characteristics of working street children: (i) our sample from Mwanza (hereafter, the Kidolezi sample, $\mathrm{n}=321$ ); (ii) working street children in Mwanza from the ILFS (hereafter, the ILFS Mwanza sample, $n=287$ ); and (iii) the national sample of all working street children from the ILFS (hereafter, the ILFS national sample, $n=22231$ ). First, we will compare the ILFS Mwanza to the ILFS national sample in order to control for Mwanza-specific differences. We will then compare characteristics of working street children in Mwanza by comparing the Kidolezi sample to the ILFS Mwanza sample.

\section{Empirical Results}

Of the 321 children interviewed for the Kidolezi sample, 13.1 percent do not have a permanent residence. These children live in temporary dwellings such as street pavements and verandas. Another 4.1 percent rent rooms they share with friends, but because these co-habitants are usually unrelated, the rental units cannot be considered "households". The no-household 
proportion of working street children in Mwanza is therefore about 17.2 percent of the Kidolezi sample, a group that would otherwise not be represented in household surveys (selection bias).

\section{Demographic Comparisons}

Table 1 shows selected demographic characteristic s from the Kidolezi, ILFS Mwanza, and ILFS national samples. The Kidolezi sample includes significantly more males than in either ILFS sample. This finding suggests that among no-household working children (i.e., those children not counted in the two ILFS samples), boys more quickly adapt than girls to street life without parental or any type of adult supervision. In short, the two ILFS/household samples underestimate the involvement of boys in street work.

The working children in the Kidolezi sample are, on average, older than those in the ILFS samples, a finding that is consistent with the observation that children in Tanzania, especially girls, delay entrance into the labor market to take care of their younger siblings.

If children from the Kidolezi sample have significantly more siblings than those from the two ILFS household samples, then one might wonder why the average family size for children in the Kidolezi sample is smaller. Almost half (47 percent) of the children in the Kidolezi sample are missing at least one parent compared to 19.1 percent (20.8 percent) of the children in the ILFS Mwanza (ILFS national) sample. Household surveys such as the ILFS samples overestimate the support network provided by two-parent families. Selection bias in household surveys may also lead to an underestimate of the labor market activities of orphaned children living in the streets.

\section{Educational Comparisons}

Table 2 shows selected educational characteristics from the Kidolezi, ILFS Mwanza, and ILFS national samples. A comparison of the children in the two ILFS household samples suggests that Mwanza street working children are better educated than their national counterparts, a finding supported by the work of Al-Samarrai and Reilly, 2000. But, the working street children in the Kidolezi sample are less likely to be in school and they are in lower grades than 
their ILFS Mwanza counterparts. ${ }^{5}$ Working children may be underrepresented in the ILFS Mwanza sample (evidence of selection bias) or household heads may overstate the level of educational attainment of their children, especially when surveyed by government officials (evidence of reporting bias).

Educational performance can also be measured by looking at "grade-for-age difference" (namely, the difference obtained by subtracting the sum of the child's grade and average school entrance age from the child's actual age). Akabayashi and Psacharopoulos (1999) found that Tanzanian children who work perform less well in school than those who do not work. Moreover, they are more likely to repeat grades. We find that working street children in the Kidolezi sample are, on average, 1.11 years older than typical children in their grade while those from the ILFS Mwanza sample are almost perfectly matched.

\section{Labor Market Comparisons}

Table 3 shows that the street children in the Kidolezi sample work longer (both more hours per day and more days per week) than those in both ILFS household samples. Parents who are primary respondents of household surveys may underreport the number of hours worked by their children in order to appear to be good parents. Moreover, there could be biased selectivity in the household samples in which many children working long hours are not represented.

Children in the Kidolezi sample earn significantly more than children in the ILFS household samples, in part because they work longer but also because more children in the Kidolezi sample are self-employed. About 42 percent of the children in the Kidolezi sample are self-employed compared to less than 10 percent of children in each of the two ILFS household samples. ${ }^{6}$ Employers who house and feed child workers withhold salaries as a form of payment for living expenses. Self-employed children (underrepresented in the two ILFS samples) thus tend to earn higher incomes.

\section{Health Comparisons}


We use history of work-related sickness or injury and hospital attendance as proxies for the health status of working children. Table 4 shows that working children in the Kidolezi sample are more likely to be injured than their ILFS household counterparts. Specifically, 58 percent of children in the Kidolezi sample reported a work-related injury or sickness in the previous year compared to 5 and 12 percent of children from the ILFS Mwanza and ILFS national samples, respectively. Parents or guardians in the household surveys may be tempted to underreport health problems related to their children's involvement in work, especially when children are involved in a household business.

Table 4 also shows that in the previous year working children in the Kidolezi sample visited a hospital less often than their ILFS household counterparts. Children in the Kidolezi sample, many of whom are self-employed, may not have the same support network (parents or extended family members) as do children in the ILFS household samples to arrange a hospital visit whenever injury or sickness occurs.

\section{Concluding Remarks}

Focusing on working street children, this study aims at revealing the potential bias introduced when studies of child labor are based on household surveys. We compare demographic, educational, labor market, and health characteristics of working street children obtained from the 2000 Tanzanian Integrated Labor Force Survey, a household-based survey, with the results obtained in a 2004 survey of working street children in the city of Mwanza, Tanzania.

The results reveal the possible presence of selection bias associated with household surveys. First, household surveys understate the extent of children's involvement in the street labor market. Our study finds that 17.2 percent of working street children do not belong to households. These children, who are excluded from the household-based ILFS samples, are 
disproportionately male. The gender ratio of working street children in our study is thus very different from the gender ratio in the two household-based ILFS samples.

The working children in our study have lower educational attainment. Specifically, despite their older age, a lower proportion of children attend school compared to those from the household samples. They are also several grades behind their ILFS counterparts. Moreover, we find that among children in our study, educational attainment of girls is higher than that of boys, whereas just the opposite is true among children in the two ILFS samples. Parents (who are usually the primary interviewees in household surveys) may be tempted to inflate the educational attainment of boys who are perceived as better providers than girls in Tanzania.

Children in our sample work significantly longer hours than those in the two ILFS samples. We find gender differences in the likelihood a child will engage in self-employed street work. There are no such differences in the ILFS samples. The former outcome suggests that boys become independent much faster than girls in the absence of familial support.

Finally, we find that health attributes of children in our sample are significantly worse than those in the ILFS samples.

In summary, the comparisons suggest the existence of both selection and reporting bias. While household surveys may provide useful labor information at the national level, their approach and methodology limit their applicability, especially when studying complex and culture-specific phenomena such as street work. As a result, empirical analysis based on household survey data may not fully reflect the harsh realities faced by working street children in developing countries. 
Table 1. Selected Demographic Differences Between the Kidolezi and ILFS Samples

\begin{tabular}{cccc}
\hline & \multicolumn{3}{c}{ Averages } \\
Variable & Kidolezi & $\begin{array}{c}\text { ILFS } \\
\text { Mwanza }\end{array}$ & $\begin{array}{c}\text { ILFS } \\
\text { National }\end{array}$ \\
\hline Age & 12.76 & $10.86^{\mathrm{a}}$ & $10.64^{\mathrm{a}}$ \\
Sex $[$ male $=1]$ & .704 & $.557^{\mathrm{a}}$ & $.543^{\mathrm{a}}$ \\
Number of siblings & 3.93 & $1.59^{\mathrm{a}}$ & $2.24^{\mathrm{a}}$ \\
Family size & 5.23 & $7.23^{\mathrm{a}}$ & $7.05^{\mathrm{a}}$ \\
& & & \\
\hline
\end{tabular}

${ }^{\mathrm{a}}$ ILFS average is significantly different from the Kidolezi average $(\mathrm{a}=.05)$. 
Table 2. Selected Educational Differences Between the Kidolezi and ILFS Samples

\begin{tabular}{|c|c|c|c|}
\hline Variable & Kidolezi & $\begin{array}{c}\text { Averages } \\
\text { ILFS } \\
\text { Mwanza }\end{array}$ & $\begin{array}{c}\text { ILFS } \\
\text { National }\end{array}$ \\
\hline $\begin{array}{l}\text { Currently in school } \\
\quad[\text { yes }=1]\end{array}$ & .642 & $.763^{\mathrm{a}}$ & $.590^{\mathrm{b}}$ \\
\hline Grade & 2.53 & $4.08^{\mathrm{a}}$ & $3.52^{\mathrm{a}, \mathrm{b}}$ \\
\hline Grade-for-age difference & 1.11 & $.037^{\mathrm{a}}$ & $.969^{\mathrm{b}}$ \\
\hline
\end{tabular}

${ }^{a}$ ILFS average is significantly different from the Kidolezi average $(a=.05)$.

${ }^{\mathrm{b}}$ ILFS national average is significantly different from the ILFS Mwanza average $(\mathrm{a}=.05)$. 
Table 3. Selected Labor Market Differences Between the Kidolezi and ILFS Samples

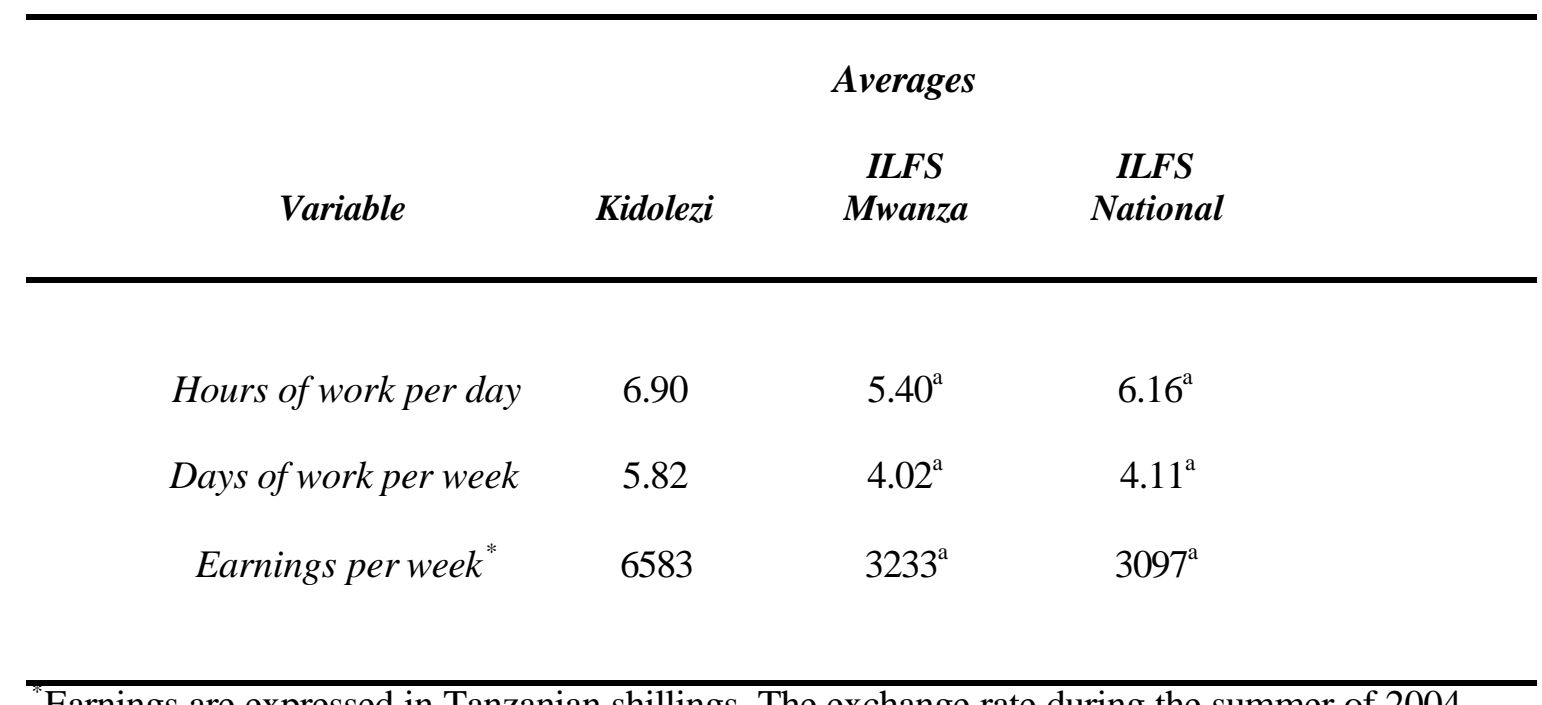

Earnings are expressed in Tanzanian shillings. The exchange rate during the summer of 2004 was 1100 Tanzanian shillings for one U.S. dollar.

${ }^{a}$ ILFS average is significantly different from the Kidolezi average $(a=.05)$. 
Table 4. Selected Health Differences Between the Kidolezi and ILFS Samples

\begin{tabular}{|c|c|c|c|}
\hline Variable & Kidolezi & $\begin{array}{c}\text { Averages } \\
\text { ILFS } \\
\text { Mwanza }\end{array}$ & $\begin{array}{c}\text { ILFS } \\
\text { National }\end{array}$ \\
\hline $\begin{array}{l}\text { Visits to hospital } \\
\text { (last } 12 \text { months) }\end{array}$ & .75 & $2.32^{\mathrm{a}}$ & $1.93^{\mathrm{a}}$ \\
\hline $\begin{array}{c}\text { Work -related injury } \\
\text { or sickness } \\
\text { (last } 12 \text { months) } \\
\text { [yes }=1]\end{array}$ & .578 & $.049^{\mathrm{a}}$ & $.118^{\mathrm{a}, \mathrm{b}}$ \\
\hline
\end{tabular}

${ }^{\mathrm{a}}$ ILFS average is significantly different from the Kidolezi average $(\mathrm{a}=.05)$.

${ }^{\mathrm{b}}$ ILFS national average is significantly different from the ILFS Mwanza average $(\mathrm{a}=.05)$. 


\section{References}

Admassie, A. (2002) "Explaining the High Incidence of Child Labor in Sub-Saharan Africa." African Development Review, Vol. 14, No. 2, pp. 251-275.

Akabayashi, H. and G. Psacharopoulos (1999) “The Trade-off Between Child Labor and Human Capital Formation: A Tanzanian Case Study.” Journal of Developmental Studies, Vol. 35, No. 5, pp. 120-140.

Al-Samarrai, S. and B. Reilly, (2000) "Urban and Rural Differences in Primary School Attendance: An Empirical Study in Tanzania." Journal of African Economies, Vol. 9, No. 4, pp. 430-474.

Arndt, C. and J.D. Lewis (2000) "The Macro Implications of HIV/AIDS in South Africa: A Preliminary Assessment.” South African Journal of Economics, Vol. 68, No. 5, pp. 856-887.

Arndt, C. and P. Wobst (2002) "HIV/AIDS and the Labor Market in Tanzania." Trade and Macroeconomic Division, IFPRI, TMD Discussion Paper No. 102.

Beegle, K., R. Dehejia, and R. Gatti (2205) "Why Should We Care About Child Labor? The Education, Labor Market, and Health Consequences of Child Labor.” World Bank Policy Research, Working Paper No. 3479.

Blunch, N. and D. Verner (1999) "Revisiting the Link Between Poverty and Child Labor: The Ghanaian Experience." Center for Labour Market and Social Research, Aarhus School of Business, CLS Working Papers Nos. 1-3. 
Canagarajah, S. and H. Coulombe (1999) "Child Labor and Schooling in Ghana." World Bank Policy Research, Working Paper No. 1844.

Fassa, A., L.A. Facchini, M.M. Dall' Agnol, and D. Christiani (1999) “Child Labor and Health: Problems and Perspectives." International Journal of Occupational and Environmental Health, Vol. 6, No. 1, pp. 55-62.

Grootaert, C. (1998) “Child Labor in Cote d'Ivoire: Incidence and Determinants.” World Bank Policy Research, Working Paper No. 569204.

Gustafsson-Wright, E. and H.H. Pyne (2002) “Gender Dimensions of Child Labor and Street Children in Brazil.” World Bank Policy Research, Working Paper No. 2897.

Hecht, T. (1998) At Home in the Street: Street Children of Northeast Brazil. Cambridge: Cambridge University Press.

ILO (2000) “Questionnaire: Survey of Children Working on the Street.” St. Petersburg Action Committee on the Elimination of Child Labor.

Jensen, P. and H.S. Nielsen (1997) "Child Labour or School Attendance? Evidence from Zambia.” Journal of Population Economics, Vol. 10, No. 4, pp. 407-424.

Lopez-Acevedo, G. (2002) “School Attendance and Child Labor in Ecuador.” World Bank Policy Research, Working Paper No. 2939.

Patrinos, H.A. and G. Psacharopoulos (1995) "Educational Performance and Child Labor in Paraguay.” International Journal of Educational Development, Vol. 15, No. 1, pp. 47-60.

Patrinos, H.A. and G. Psacharopoulos (1997) "Family Size, Schooling and Child Labor in Peru: An Empirical Analysis.” Journal of Population Economics, Vol. 10, No. 4, pp. 387-405. 
Ray, R. (2000) “Child Labor, Child Schooling, and Their Interaction with Adult Labor: Empirical Evidence from Peru and Pakistan.” The World Bank Economic Review, Vol. 14, No. 2 , pp. 347-367.

Ray, R. (2002) "The Determinants of Child Labor and Child Schooling in Ghana." Journal of African Economies, Vol. 11, No. 4, pp. 561-590.

Terre des Hommes (2002) "Needs Assessment of Children Working in the Streets of Kabul." ASCHIANA Street Children Project. 


\section{Footnotes}

1. As of January 2005, 192 countries had ratified UN conventions on the rights of the child, whose signatories are required to legally ban child labor.

2. Some of the questions were taken from the survey questionnaires of children working in the streets of St. Petersburg, Russia (ILO, 2000) and of Kabul, Afghanistan (Terres des Hommes, 2002) as well as from the Tanzanian ILFS (2000).

3. The interviews were restricted to working street children and did not include children involved in other forms of child labor, such as domestic work or agricultural farm work.

4. To ensure a random selection of working street children, the city of Mwanza was divided into quadrants. Every interview day was then divided into three two-hour intervals: 9 a.m. to 11 a.m., 1 p.m. to 3 p.m., and 5 p.m. to 7 p.m. Each quadrant was covered equally during all time intervals.

5. The gender differences in school enrollment are striking. In the Kidolezi sample, 79 percent of girls are in school compared to 58 percent of boys. However, among children in the ILFS Mwanza (national) sample, 83 (60) percent of boys are in school compared to 70 (58) percent of girls.

6. The gender differences are again noteworthy. In the Kidolezi sample, 52 percent of boys are self-employed compared to only 17 percent of girls. In the two ILFS household samples, there are no discernable gender differences. 